\title{
Multiple plastic stents for benign extrahepatic biliary strictures: report of a case
}

\author{
Łukasz Rdzanek ${ }^{1}$, Piotr Kalinowski ${ }^{1}$, Sławomir Kozieł ${ }^{1}$, Konrad Kobryń ${ }^{1}$, Bogna Ziarkiewicz-Wróblewska ${ }^{2}$, \\ Waldemar Patkowski ${ }^{1}$, Marek Krawczyk ${ }^{1}$ \\ ${ }^{1}$ Department of General, Transplant and Liver Surgery, Medical University of Warsaw, Warsaw, Poland \\ ${ }^{2}$ Department of Pathology, Medical University of Warsaw, Warsaw, Poland
}

Videosurgery Miniinv 2015; 10 (2): 342-346

DOI: $10.5114 /$ wiitm.2015.49820

\begin{abstract}
The etiology of benign bile duct strictures is heterogeneous. Many of them may be secondary to intraoperative injury such as injuries occurring during laparoscopic cholecystectomy. The spectrum of symptoms at presentation varies from subclinical disease with elevation of liver function tests to complete biliary obstruction with jaundice and hyperbilirubinemia or external biliary fistula in the case of bile duct injury. Long-term consequences may lead to secondary biliary cirrhosis. This publication reports a case of a 49-year-old woman with symptomatic gallstone disease who underwent a laparoscopic cholecystectomy in November 2006. She underwent endoscopic retrograde cholangio-pancreatography due to jaundice, fever and abdominal pain. Then she underwent left hemi-hepatectomy in October 2008 and transplantation of the liver in January 2014. Traditionally, surgical repair has been the preferred approach in benign biliary strictures, but there is an increasing trend for use of minimally invasive endoscopic therapy in these patients.
\end{abstract}

Key words: multiple plastic stents, bile duct strictures, bile duct injury.

\section{Introduction}

Bile duct injury during laparoscopic or open cholecystectomy is the most common cause of post-operative benign biliary stricture. Other types of surgery such as bile duct reconstruction or orthotopic liver transplantation (OLTX), procedures where various types of biliary anastomoses are used, may also be complicated by strictures in biliary anastomosis [1]. In the case of strictures of hepaticojejunal anastomoses after primary correction of bile duct injuries, the use of double balloon enteroscopy is a useful method for diagnosis and treatment [2]. Other causes are recurrent cholangitis, chronic pancreatitis, primary sclerosing cholangitis, abdominal trauma, ischemic injury, sarcoidosis, chemotherapy, radiation therapy,
HIV cholangiopathy, vasculitis, infection, dysfunction of the sphincter of Oddi, choledochal cysts, papillary stenosis and the Mirizzi syndrome [3].

Some benign biliary strictures are asymptomatic, with mild elevation of liver function tests. Other patients present with complete biliary obstruction with jaundice and hyperbilirubinemia. Generally, recurrent cholangitis may lead to secondary biliary cirrhosis and finally to end-stage liver disease [4]. There are 5 stages of benign biliary stricture according to Bismuth [5] (Table I).

\section{Case report}

In 2006 a 49-year-old woman with symptomatic gallstone disease underwent a laparoscopic cho-

\section{Address for correspondence}

Łukasz Rdzanek MD, Department of General, Transplant and Liver Surgery, Medical University of Warsaw, 1 A Banacha St,

02-097 Warsaw, Poland, phone: +48 696039 559, e-mail: drlukaszrdzanek@drlukaszrdzanek.pl 
lecystectomy. After 2 years in 2008 she presented with fever, abdominal pain, pruritus and jaundice. She underwent endoscopic therapy with placement of plastic stents in the biliary tree. In October 2008 she underwent laparotomy because of suspected hepatocellular carcinoma found on abdominal computed tomography (CT). During laparotomy, multiple lesions $0.5-1 \mathrm{~cm}$ in diameter were found in the left lobe of the liver. Intraoperative histopathology confirmed the diagnosis of hepatocellular carcinoma (HCC), and the surgeons performed left hemihepatectomy. Final histopathology confirmed the intraoperative findings (Photo 1).

Four weeks after the operation the patient presented with jaundice and cholangitis again. Endoscopic retrograde cholangiopancreatography (ERCP), sphincterotomy and stenting were performed. Subsequently the patient had plastic stents changed many times in 2009 and 2010 because of recurrent cholangitis and jaundice. Time intervals between each procedure ranged from a few weeks to months. In 2010 the same histopathological specimen was analyzed once again, and the diagnosis did not confirm cancer but chronic inflammation (Photos 2, 3).

Assessment of the liver and biliary tree in magnetic resonance (MR) and $C T$ did not support the possibility of a surgical approach because of the anatomical location of the stricture. Unfortunately the stricture was deep in the parenchyma of the liver, and there was no technical way to perform a repair operation (Photo 4).

From 2010 until 2013 the patient still had a problem with recurrent cholangitis and still had repeat-

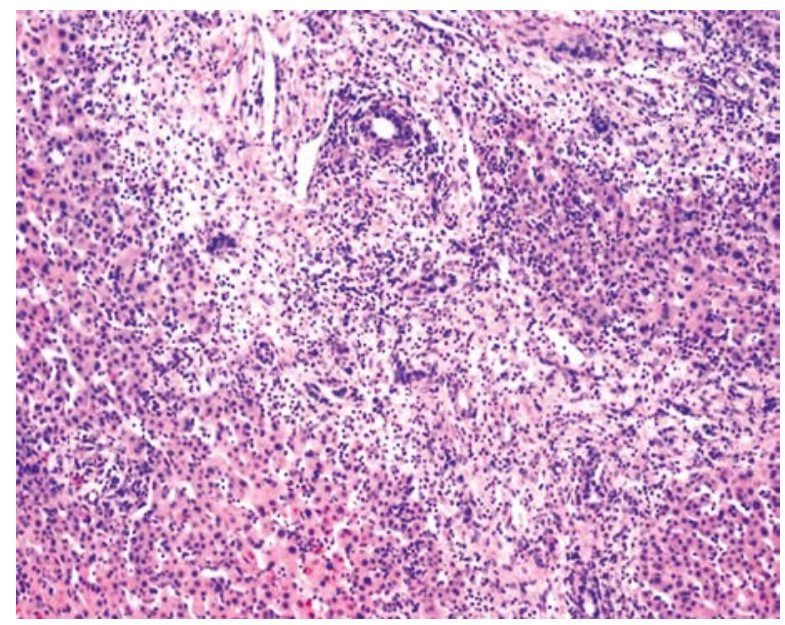

Photo 2. Inflammation in the liver of the patient - histopathological specimen - operation 2008
Table I. Bismuth classification of benign biliary strictures

\begin{tabular}{|cr|}
\hline Stage & Location of stricture \\
\hline I & More than $2 \mathrm{~cm}$ distal to the hepatic bifurcation \\
\hline II & Less than $2 \mathrm{~cm}$ distal to the hepatic bifurcation \\
\hline III & At the level of the hepatic bifurcation \\
\hline IV & Involves left or right hepatic duct \\
\hline V & Extends into the left or right hepatic branch ducts \\
\hline
\end{tabular}

ed multiple stent treatments. Endoscopic retrograde cholangiopancreatography and replacement of the stents needed to be repeated at several-week intervals (Photo 5).

In 2013 gastroscopy revealed esophageal varices - symptoms of cirrhosis of the liver. In October 2013

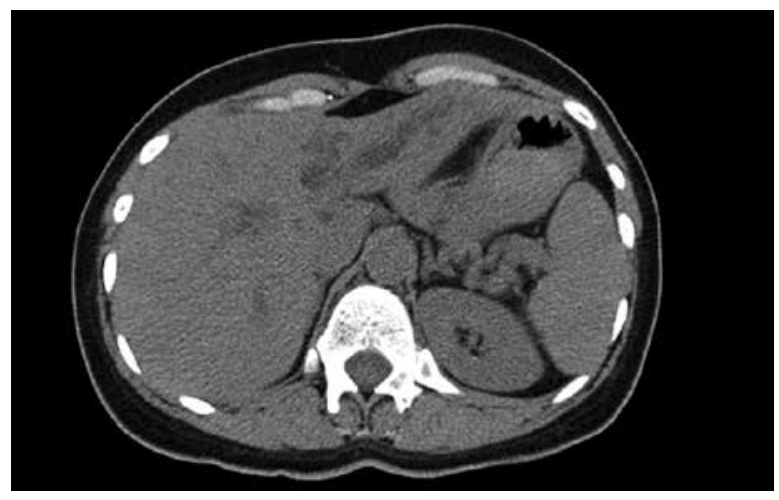

Photo 1. Computed tomography scan of the liver (01.09.2008) - suspected HCC in the left lobe of the liver

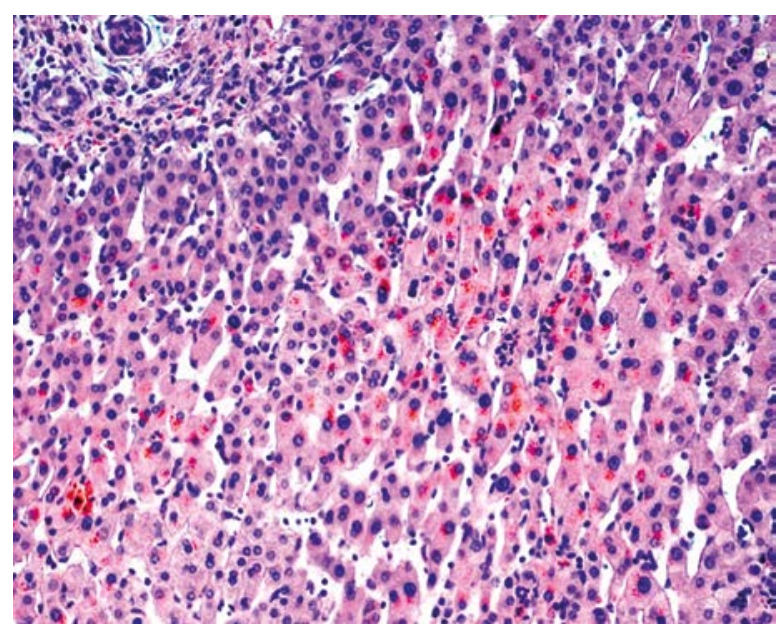

Photo 3. Cholestasis in the same liver - histopathological specimen - operation 2008 


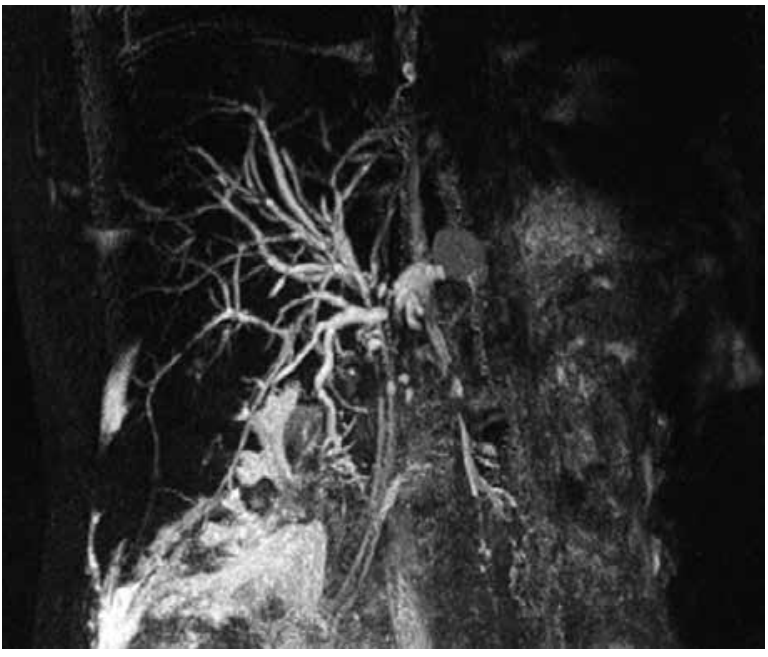

Photo 4. Magnetic resonance 06.2013 - biliary tree with plastic stents

after another episode of cholangitis, the patient had symptoms of liver failure with jaundice, ascites and hypoalbuminemia. The decision was made to qualify the patient for liver transplantation. In January 2014 the patient underwent orthotopic liver transplantation with a good outcome (Photos $6 \mathrm{~A}, \mathrm{~B}$ ).

\section{Discussion}

In the presented case the extrahepatic stricture was a consequence of the cholecystectomy performed in 2006 (Bismuth I/II), and the intrahepatic stricture (Bismuth $\mathrm{V}$ ) appeared probably after the

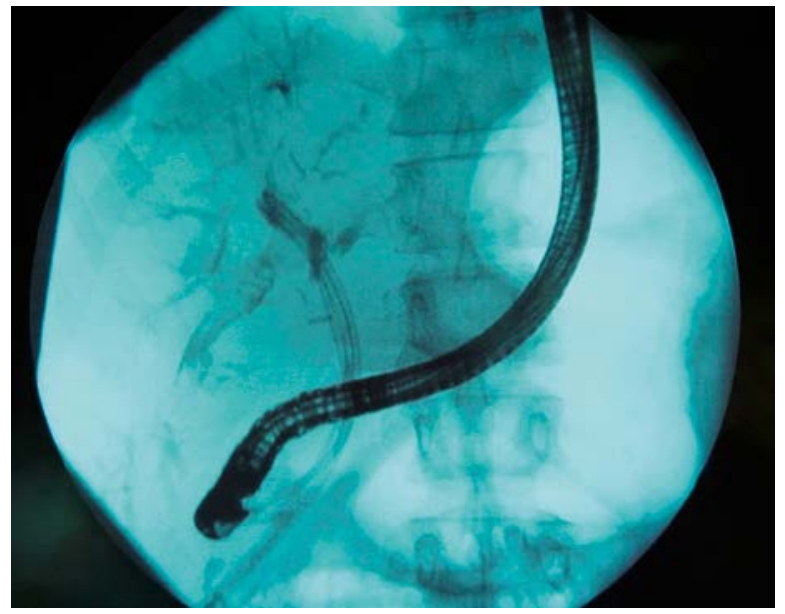

Photo 5. Cholangiography done during endoscopic procedure (24.10.2013). Three plastic stents in the biliary tree

second operation, which was the left hemihepatectomy.

In cases of malignant obstruction, surgical treatment is associated with the lowest rates of complications such as cholangitis (about 10\%) when compared to other methods of treatment. The endoscopic treatment with placement of multiple plastic stents is associated with cholangitis in $20.3 \%$ of cases compared to $39.5 \%$ following uncovered self-expandable metallic stents (SEMS) and 36.0\% when a single plastic stent is placed [6] (Photos $7 \mathrm{~A}, \mathrm{~B}$ ).

Short-term results including clinical success, morbidity, mortality and quality of life are similar for plas-

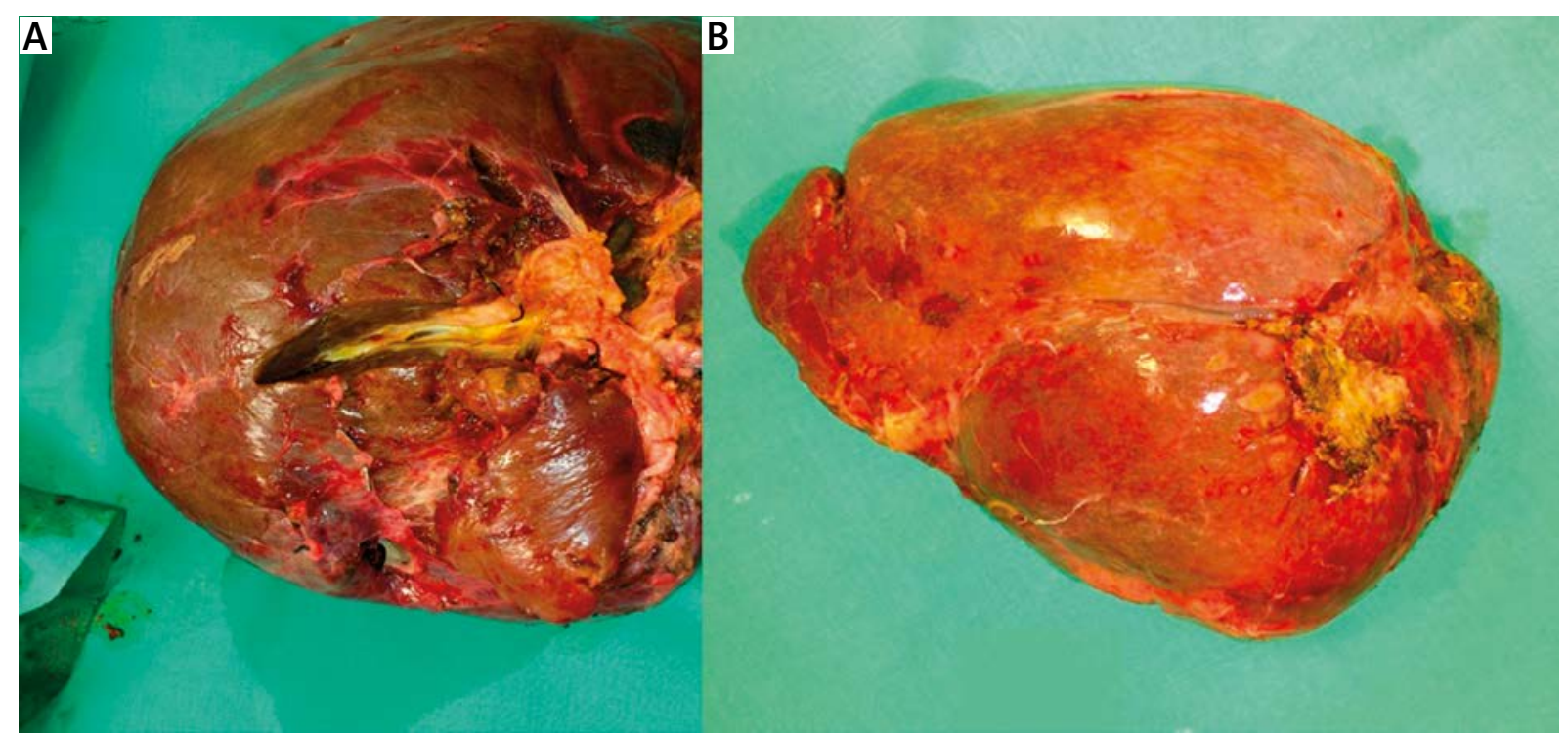

Photo 6 A-B. Liver of the patient after hepatectomy during orthotopic liver transplantation 


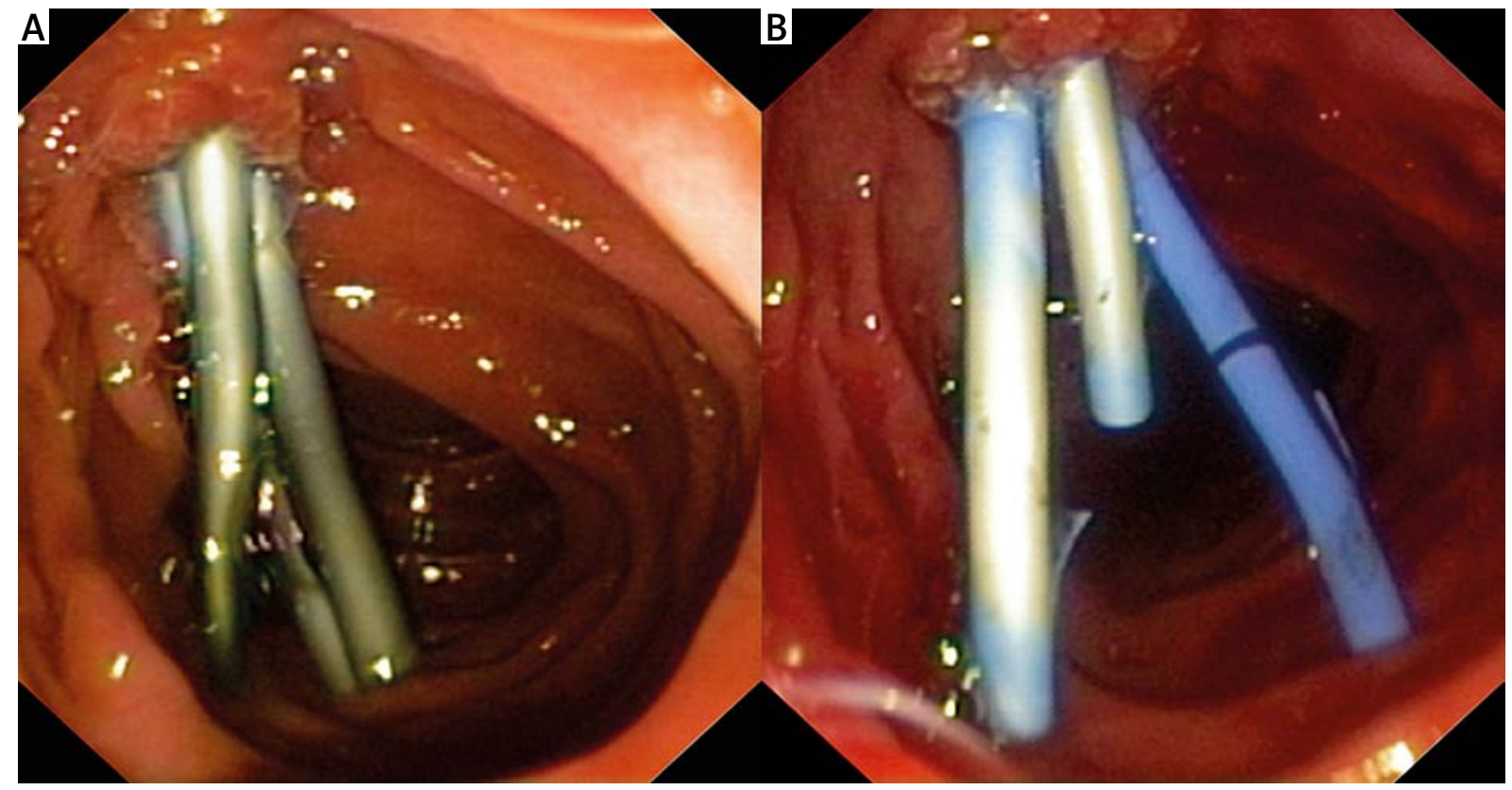

Photo 7 A-B. Multiple plastic stents

tic stents and SEMS. Early complications are similar and develop in $5 \%$ of patients. The most common complications are cholangitis, pancreatitis, bleeding, perforation, early stent migration and renal failure [7].

Late complications such as stent dysfunction in cases of common bile duct (CBD) stricture are more frequent after placement of plastic stents (41\%) compared to uncovered SEMS (27\%), partially covered SEMS (20\%) and fully covered SEMS (20\%). Stent migration is observed in $5 \%$ of cases of plastic stents, $1 \%$ of uncovered SEMS and $20 \%$ of fully covered SEMS. The European Society of Gastrointestinal Endoscopy (ESGE) recommends treatment of CBD strictures with multiple plastic stents with repeated intervention. Treatment with SEMS has a higher risk of fatal septic complications [8]. Plastic stents are often used also for the treatment of bile leaks after laparoscopic cholecystectomy with efficiency of 90\% [9].

Palliative treatment of malignant CBD obstruction in cases of endoscopic biliary drainage is effective in $>80 \%$. Comparison of endoscopic vs. surgical biliary cancer treatment showed no differences in terms of technical and therapeutic success, survival or quality of life [10].

If there are no other options of treatment, percutaneous ultrasound-guided drainage of the biliary tree in palliative treatment of mechanical jaundice is a well-tolerated method with only a few complications [11].

\section{Conclusions}

Surgical treatment is a treatment of choice in benign biliary strictures and is still the best way to prevent long-term consequences of chronic low-grade obstruction that may eventually lead to secondary biliary cirrhosis and end-stage liver disease. In patients who are not good candidates for surgery, endoscopic biliary stenting is an alternative treatment method that has good outcomes. However, biliary stenting even with multiple stents placed selectively provides only a temporary solution of the problem. It is not possible to achieve good long-term results and prevent long-term complications of strictures with stent treatment only. In selected patients with secondary biliary cirrhosis, orthotopic liver transplantation may be the ultimate solution.

\section{Conflict of interest}

The authors declare no conflict of interest.

\section{References}

1. Judah JR, Draganov PV. Endoscopic therapy of benign biliary structures. World J Gastroenterol 2007; 13: 3531-9.

2. Varabei A, Arlouski Y, Vizhinis E, et al. The use of double balloon enteroscopy for diagnosis and treatment of strictures of hepaticojejunal anastomoses after primary correction of bile duct injuries. Videosurgery Miniinv 2014; 9: 219-25. 
3. Martin RF, Rossi RL. Bile duct injuries. Spectrum mechanisms of injury, and their prevention. Surg Clin North Am 1994; 74: 781-803.

4. Warshaw AL, Schapiro RH, Ferrucci JT. Persistent obstructive jaundice, cholangitis, and biliary cirrhosis due to common bile duct stenosis in chronic pancreatitis. Gastroenterology 1976; 70: $562-7$.

5. Bismuth H. Postoperative strictures of the bile duct. In: The biliary tract. Blumgart LH (ed.) Churchill Livingstone, Edinburgh 1982; 209-18.

6. van Boeckel PG, Vleggaar FP, Siersema PD. Plastic or metal stents for benign extrahepatic biliary stricture: a systematic review. BMC Gastroenterology 2009; 9: 96.

7. Moss AC, Morris E, Leyden JU, et al. Do the benefits of metal stents justify the cost? A systematic review and meta-analysis of trials comparing endoscopic stents for malignant biliary obstruction. Eur J Gastroenterol Hepatol 2007; 19: 1119-24.

8. Dumonceau JM, Tringali A, Blero D. Biliary stenting: indication, choice of stents and results. European of Gastrointestinal Endoscopy (ESGE) clinical guideline. Endoscopy 2012; 44: 277-98.

9. Jamry A, Brocki M, Santorek-Strumiłło E, Wcisło S. Endoscopic therapy for biliary leak after laparoscopic cholecystectomy diagnostic limitations and choice of therapy option. Videosurgery Miniinv 2007; 2: 24-8.

10. Moss AC, Morris E, Leyden J, et al. Malignant distal biliary obstruction: a systematic review and meta-analysis of endoscopic and surgical bypass results. Cancer Treat Rev 2007; 33: 213-21.

11. Bednarek M, Budzyński P, Poźniczek M, Rembiasz K. Percutaneous ultrasound-guided drainage of the biliary tree in palliative treatment of mechanical jaundice: 17 years of experience. Videosurgery Miniinv 2012; 7: 193-6.

Received: 16.09.2014, accepted: 21.10.2014. 